\title{
Suppression of local corrosion of steel, brass and copper with IFKhAN-114 volatile inhibitor
}

\author{
V.I. Vigdorovich, ${ }^{13}$ L.E. Tsygankova, ${ }^{2}$ L.G. Knyazeva, ${ }^{1}$ A.V. Dorokhov, ${ }^{1}$ \\ A.N. Dorokhova ${ }^{2}$ and M.V. Vigdorowitsch ${ }^{4}$ \\ ${ }^{1}$ All-Russian Scientific Research Institute of Use of Machinery and Oil Products, \\ Novo-Rubezhnyi per., 28, Tambov, 392022, Russian Federation \\ ${ }^{2}$ Derzhavin State University, Internatsyonalnaya str., 33, Tambov, 392000, \\ Russian Federation \\ ${ }^{3}$ Tambov State Technical University, Sovetskaya str., 106, Tambov, 392000, \\ Russian Federation \\ ${ }^{4}$ Angara GmbH, In der Steele 2, D-40599, Düsseldorf, Germany \\ *E-mail: vits21@mail.ru
}

\begin{abstract}
The possibility of preventing local corrosion of carbon steel St3, copper M2 and two-phase $(\alpha+\beta)$ brass L62 in an atmosphere with $100 \%$ relative humidity of air containing up to 0.6 vol. $\% \mathrm{CO}_{2}, 60 \mathrm{mg} / \mathrm{m}^{3} \mathrm{NH}_{3}, 30 \mathrm{mg} / \mathrm{m}^{3} \mathrm{H}_{2} \mathrm{~S}$ and IFKhAN-114 volatile corrosion inhibitor (VCI) was studied. The suppression of the local corrosion of carbon steel St3 and copper, which are constituents of the steel/copper, steel/brass and copper/ brass macro galvanic pairs, was evaluated in the presence of IFKhAN-114 in the second series of the experiments. The combined metal samples consisting of an outer metal ring $2.8 \mathrm{~cm}$ in diameter, into which a washer of metal of a different nature with a diameter of $2.0 \mathrm{~cm}$ was inserted through a tight fit, were used for corrosion tests of contact galvanic pairs. When assessing the effect of VCI on the overall corrosion rate of the above-mentioned steel/copper, steel/brass, and copper/brass galvanic pairs, their integral corrosion losses for $240 \mathrm{~h}$ per unit time were taken into account. Photography of the nature of the damage to the surface of the components of galvanic pairs was carried out after completion of corrosion tests and removal of corrosion products. It was shown that local corrosion of the macro-pair components in the form of ulcers and numerous pits observed in the presence of $0.60 \% \mathrm{CO}_{2}$ or $0.2 \% \mathrm{CO}_{2}+20 \mathrm{mg} / \mathrm{m}^{3} \mathrm{NH}_{3}+10 \mathrm{mg} / \mathrm{m}^{3} \mathrm{H}_{2} \mathrm{~S}$ in uninhibited air, was hindered almost completely in the presence of the IFKhAN-114 inhibitor. The corrosion of these metals under these conditions is uniform, and the protective effect of the inhibitor is, \%: 74 (steel), 99 (brass) and 60 (copper).
\end{abstract}

Key words: ulcer corrosion, pitting, atmosphere, ammonia, hydrogen sulphide, carbon dioxide, steel, brass, copper, volatile inhibitors, suppression.

Received: September 7, 2018. Published: January 19, 2019

doi: $\underline{10.17675 / 2305-6894-2019-8-1-4}$ 


\section{Introduction}

It was shown earlier in a number of works [1-3] that volatile corrosion inhibitors (VCI) of IFKhAN series efficiently suppress the atmospheric corrosion of steel [1-3], brass [3] and copper [3] under conditions of $100 \%$ relative humidity at the background and multiply increased concentrations of corrosion stimulants (CSs) $\mathrm{NH}_{3}, \mathrm{H}_{2} \mathrm{~S}$ and $\mathrm{CO}_{2}$. Simultaneous presence of any two CSs reduces the effectiveness of some representatives of this series (IFKhAN-118 [2,3]) with respect to the rate of general corrosion and practically does not change that of other ones (IFKhAN-114 [2,3]). The presence of all three CSs increases the efficiency of VCI in a number of cases. However, the presence of all these corrosion stimulants separately or together, as a rule, causes significant local damage to the surface of metals [2,3]. Ulcers and numerous pits are formed on the surface of steel (St3), biphasic $(\alpha+\beta)$ brass and copper in 10-day tests. A similar picture takes place also in the presence of contacting pairs of these metals. The presence of the IFKhAN VCI can effectively suppress a local damage of carbon steel, brass and copper under conditions of atmospheric corrosion in the presence of elevated concentrations of stimulating micro impurities of $\mathrm{NH}_{3}, \mathrm{H}_{2} \mathrm{~S}$ and $\mathrm{CO}_{2}$ in the air with $100 \%$ relative humidity $(\mathrm{H})$ in a number of cases.

The purpose of this paper is to assess the possibility of suppressing corrosion of steel and copper by a volatile corrosion inhibitor both without their mutual contacts and as constituents of contact macrogalvanic pairs under atmospheric conditions in the presence of higher concentrations of $\mathrm{CO}_{2}, \mathrm{NH}_{3}$ and $\mathrm{H}_{2} \mathrm{~S}$ in air with $100 \%$ relative humidity.

\section{Experimental}

The IFKhAN-114 corrosion inhibitor (a non-equimolar mixture of polyaniline and benzoic acid (TU 24155-114-16424386-2018) with $P_{\text {saturated vapor }}<0.130 \mathrm{~Pa}$, developed at A.N. Frumkin Institute of Physical Chemistry and Electrochemistry, Russian Academy of Sciences, which is product of hazard class III, was used as the VCI. Corrosion tests were carried out at room temperature in hermetically sealed desiccators with a volume of 7 liters, into which two containers were placed. The investigated VCI was located in one of the containers and saturating the gas phase due to evaporation. Dilute solutions of substances necessary to create the maximum permissible levels of micro impurities in air (corrosion stimulants $\mathrm{CO}_{2}, \mathrm{H}_{2} \mathrm{~S}$ and $\mathrm{NH}_{3}$ ) for livestock buildings or slightly higher than their equilibrium concentrations were located in another container. A special technique was developed that allowed for a specified partial pressure of the CSs in the gas phase and their equilibrium concentrations in the liquid, using Henry's law, to accurately calculate the amounts of initial substances required for the synthesis of CSs in order to create the necessary equilibrium concentration of a single CS in the gas phase separately. To create atmospheres containing several CSs simultaneously, similar containers for their 
production were arranged outside the desiccator, and the atmospheres were saturated with the CSs obtained by means of hoses with overlapping cranes inserted through the hole in the desiccator cover. The duration of corrosion tests conducted at room temperature was $240 \mathrm{~h}$. Corrosion products on all metal surfaces were removed after completion of the experiment with an inhibited $10 \% \mathrm{HCl}$ solution containing additionally $3 \mathrm{~g} / \mathrm{L}$ hexamethylenetetramine and $1 \mathrm{~g} / \mathrm{L} \mathrm{KJ}$. Metal samples $(30 \times 25 \times 3 \mathrm{~mm})$ polished to the $6^{\text {th }}$ grade, degreased with acetone, washed and dried with filter paper were used in one series of corrosion tests.

Combined metal samples consisting of an outer metal ring $2.8 \mathrm{~cm}$ in diameter, into which a washer of a different metal with a diameter of $2.0 \mathrm{~cm}$ was inserted through a tight fit, were used for corrosion tests of contact galvanic pairs. The thickness of the sample was $0.3 \mathrm{~cm}$. The ratio of the working surfaces $S_{\text {ring }}: S_{\text {washer }}$ was $1: 0.75$. Their integral corrosion losses for $240 \mathrm{~h}$ given to a unit of time, were taken into account when assessing the effect of VCI on the above-mentioned components of the steel/copper, steel/brass, and copper/brass macro galvanic pairs.

Photography of the nature of the damage to the surface of the components of the galvanic pairs was carried out after completion of the corrosion tests and removal of corrosion products.

The chemical composition of the metals under study was as follows: St3 steel, wt.\%: C 0.20, Mn 0.51, Si 0.15, P 0.04, S 0.05, Cr 0.32, Ni 0.21, Cu 0.23, Fe 98.29; M2 copper, wt.\%: $\mathrm{Al} \leq 0.002, \mathrm{Zn} \leq 0.005, \mathrm{Mn} \leq 0.01, \mathrm{Cr} \leq 0.05, \mathrm{Si} \leq 0.01, \mathrm{Zr} \leq 0.05, \mathrm{Cu} 99.7$; twophase $(\alpha+\beta)$ brass L62, wt.\%: Zn 22.5, Mn 2.9, Fe 2.0, Al 4.1, Cu - rest.

\section{Results and discussion}

Images of the samples of St3 steel $(a, b)$ and M2 copper (c,d) after completion of the corrosion tests in the air atmosphere $(\mathrm{H}=100 \%)$ containing carbon dioxide $(0.60 \%$ by volume) and ammonia $\left(60 \mathrm{mg} / \mathrm{m}^{3}\right)$ in the absence $(\mathrm{a}, \mathrm{c})$ and in the presence of IFKhAN-114 $(\mathrm{b}, \mathrm{d})$ is shown in Figure 1.

Corrosion of steel has a pronounced ulcerative character, supplemented by numerous pits (Figure 1a) in the absence of VCI. Numerous pits and wide areas of darkening are formed on the copper surface (Figure 1c) due to the formation of a surface oxide film $(\mathrm{CuO})$.

In the presence of volatile inhibitor IFKhAN-114, corrosion of steel is uniform with traces of local damage only near the hole for suspending the samples. Apparently, hardening appears during drilling, which results in activation of the metal during corrosion tests.

Local lesions are absent on the surface of copper even near the suspension hole in the presence of IFKhAN-114. Weak darkening of the metal due to the formation of $\mathrm{CuO}$ is observed, but copper corrosion is uniform. 


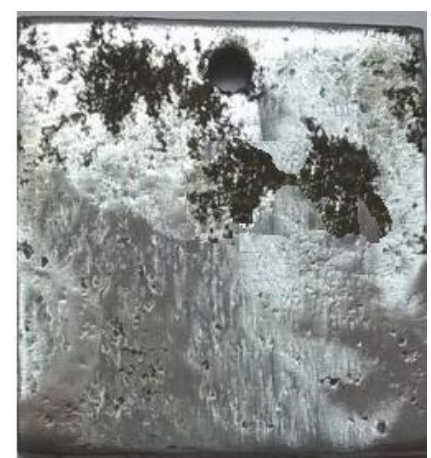

$\mathrm{a}$

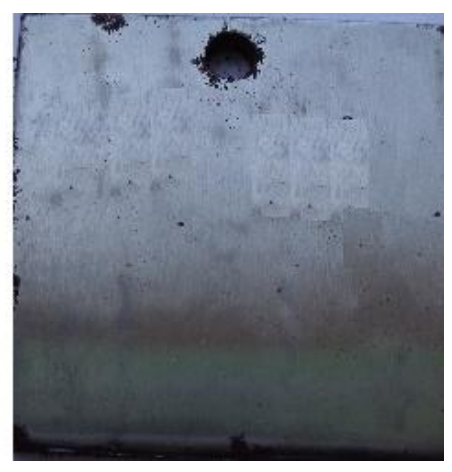

b

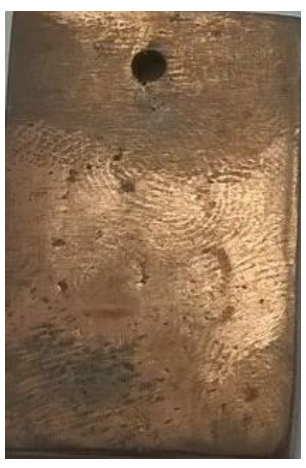

c

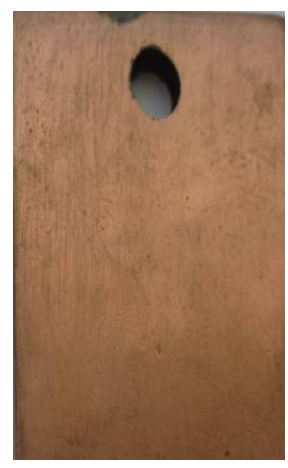

d

Figure 1. The state of the surface of steel (a,b) and copper (c,d) samples after a 240-hour corrosion attack of the air medium containing 0.60 vol. $\% \mathrm{CO}_{2}$ and $60 \mathrm{mg} / \mathrm{m}^{3} \mathrm{NH}_{3}$ at $\mathrm{H}=$ $100 \%$ in the absence $(a, c)$ and in the presence of IFKhAN-114 (b,d).

According to the corrosion test data, the protective effect $(Z, \%)$ of IFKhAN-114 for total corrosion is $85 \%$ (steel) and $75 \%$ (copper). An estimate of the value of $Z$ is given by the formula:

$$
Z=100\left[\left(K_{0}-K_{\text {Inh }}\right) / K_{0}\right]
$$

where $K_{0}$ and $K_{\text {Inh }}$ are the corrosion rates in the absence and in the presence of the inhibitor, respectively.

The character of the damage to the surface of steel and copper on replacing $60 \mathrm{mg} / \mathrm{m}^{3}$ of $\mathrm{NH}_{3}$ by $30 \mathrm{mg} / \mathrm{m}^{3} \mathrm{H}_{2} \mathrm{~S}$, the other experimental conditions being the same, is shown in Figure 2.

It follows from Figure 2a that corrosion of steel in the absence of VCI has a pronounced local character with the formation of both small and large pittings.

Corrosion of copper under these conditions (Figure 2c) proceeds without local lesions, but with darkening of a large portion of the surface due to the formation of a $\mathrm{CuO}$ film. $\mathrm{A}$ presence of IFKhAN-114 does not reduce, but even significantly increases the share of the darkened surface, which is close to $100 \%$. The protective effect of the inhibitor is about $40 \%$.

The picture of brass damage after completion of the corrosion tests is similar to that observed for copper, but the $Z$ value rises to $75 \%$.

Let us consider the results of an investigation of the state of the surface of shortcircuited components of macrogalvanic pairs under the same conditions of atmospheric corrosion. The results of the study of a morphology of the surface damage of the macropair constituents in the presence of $\mathrm{CO}_{2}$ are summarized in Figure 3. A concentration of carbon dioxide in air is 0.2 vol. \% in this case and corresponds to the composition of the medium in subsequent experiments. 
In the steel/copper contact macropairs, a local surface damage is significantly manifested on the steel ring (Figure 3a), while copper does not even have a darkening in the absence of VCI.

In the case of the steel/brass macro pair, the local lesion of steel is sharply increased up to formation of small ulcers along with pitting (Figure 3c). Specific surface lesions (Figure 3c, inner disc) also occur on brass.

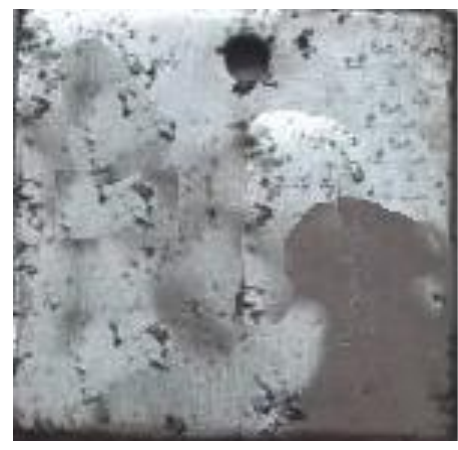

a

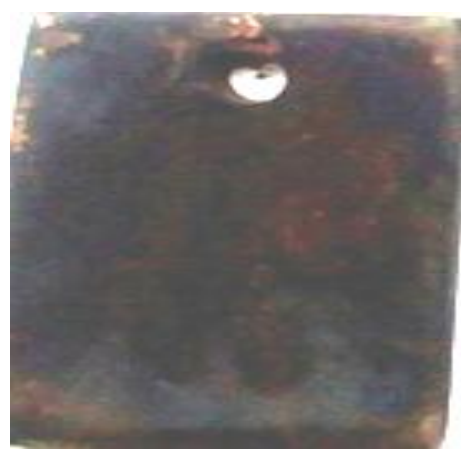

b

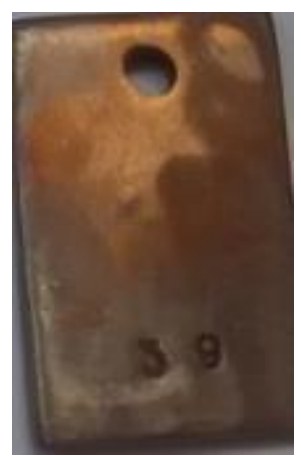

$\mathrm{c}$

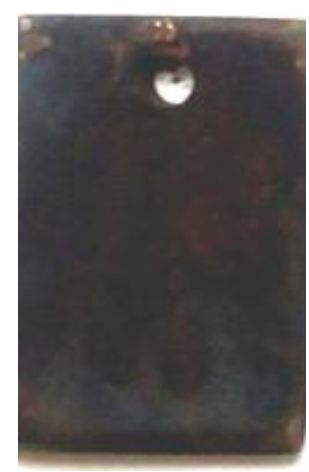

d

Figure 2. The character of the corrosion damage to the surface of steel St3 (a,b) and copper (c,d) in an atmosphere containing 0.6 vol. $\% \mathrm{CO}_{2}$ and $30 \mathrm{mg} / \mathrm{m}^{3} \mathrm{H}_{2} \mathrm{~S}$ at $\mathrm{H}=100 \%$ in the absence $(\mathrm{a}, \mathrm{c})$ and in the presence of IFKhAN-114 (b,d).

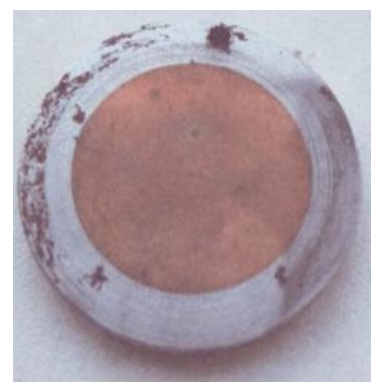

a

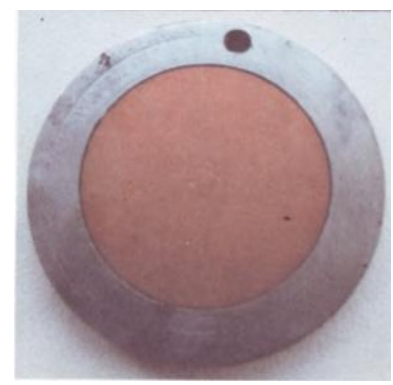

b

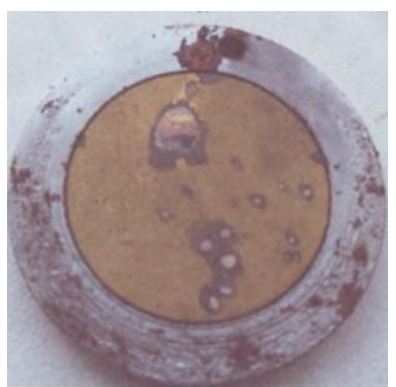

$\mathrm{c}$

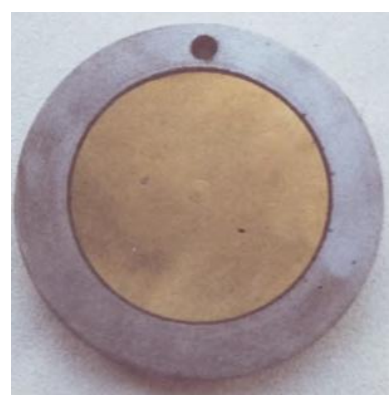

d

Figure 3. The nature of the damage to the surface of the constituents of steel/copper $(a, b)$ and steel/brass (c,d) macropairs after 240 hours of exposure to an air atmosphere containing 0.2 vol. $\% \mathrm{CO}_{2}$ in the absence (a,c) and in the presence of IFKhAN-114 (b, d), H $=100 \%$.

Local lesions of steel are not observed in the case of both macropars (Figures $3 \mathrm{~b}$ and $3 d$ ) in the presence of IFKhAN-114, but on the outer ring of the steel/copper system, small areas of darkening are observed. The surface of the components of the steel/brass macro pair does not undergo any changes during the corrosion process in the presence of IFKhAN-114 (Figure 3d).

A character of local damage to the surface of the same macro-pair, with additional introduction of $20 \mathrm{mg} / \mathrm{m}^{3}$ ammonia and $10 \mathrm{mg} / \mathrm{m}^{3}$ of hydrogen sulfide into the air 
atmosphere, is shown in Figure 4. Concentration of $\mathrm{NH}_{3}$ and $\mathrm{H}_{2} \mathrm{~S}$ in this case corresponded to the normatively admissible values for air of cattle-breeding premises $[7,8]$.

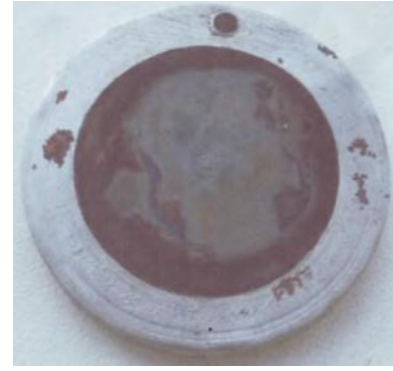

a

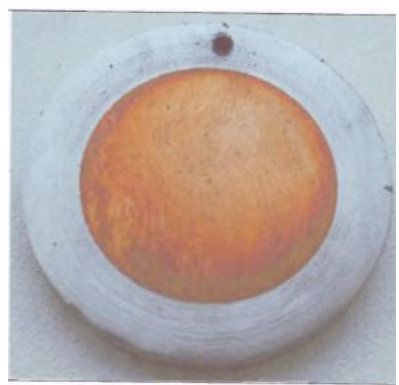

b

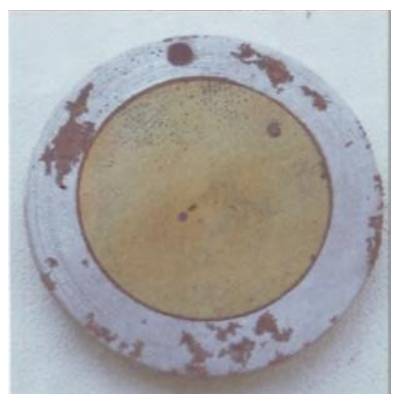

$\mathrm{c}$

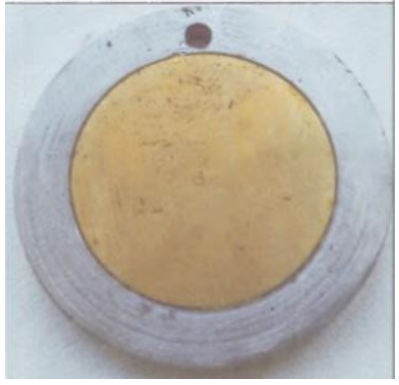

d

Figure 4. Nature of the surface damage of the components of the steel/copper $(a, b)$ and steel/brass (c,d) macro pairs after 240 hours of exposure to an air atmosphere containing 0.2 vol. $\% \mathrm{CO}_{2}+20 \mathrm{mg} / \mathrm{m}^{3} \mathrm{NH}_{3}+10 \mathrm{mg} / \mathrm{m}^{3} \mathrm{H}_{2} \mathrm{~S}$ in the absence $(\mathrm{a}, \mathrm{c})$ and in the presence $(\mathrm{b}, \mathrm{d})$ of the inhibitor IFKhAN-114 in the corrosion medium.

Local corrosion steel is also observed in a steel/copper macro pair in the presence of all three CSs, but its intensity does not increase (Figure 4a) in comparison with the conditions in Figure 3a. The surface of the inner copper disk intensely turns black, small pittings appear on it. A qualitatively similar picture is observed on the outer steel ring of the steel/brass macro pair (Figures $3 \mathrm{c}$ and $4 \mathrm{c}$ ), but the corrosion damage of the surface of the brass disk is sharply reduced (Figures $3 \mathrm{c}$ and $4 \mathrm{c}$ ).

Local damage to the components of the steel/copper and steel/brass macro pairs is generally absent in the presence of the inhibitor IFKhAN-114. Their corrosion is uniform. Data on the protective effect of the inhibitor IFKhAN-114 in the presence of the studied concentrations of micro components in the air acting as corrosion stimulators are given in the table taking into account, as a rough approximation, the uniform nature of the atmospheric corrosion of steel, copper and brass.

The calculation of the $Z$ value was again given using the integral $K_{\mathrm{i}}$ values of the macro-pairs without differentiating the corrosion rate of the constituents.

\section{Conclusion}

1. The volatile corrosion inhibitor IFKhAN-114 effectively suppresses the local corrosion of carbon steel, copper, and two-phase $(\alpha+\beta)$ brass under atmospheric conditions at a concentration of stimulating microimpurities in air (ammonia, hydrogen sulphide, carbon dioxide) many times exceeding background values.

2. A local corrosion of the steel/copper and steel/brass contact galvanic pairs in the presence of 0.2 vol. $\% \mathrm{CO}_{2}$ or 0.2 vol. $\% \mathrm{CO}_{2}+20 \mathrm{mg} / \mathrm{m}^{3} \mathrm{NH}_{3}+10 \mathrm{mg} / \mathrm{m}^{3} \mathrm{H}_{2} \mathrm{~S}$ is suppressed completely in the presence of inhibitor IFKhAN-114, corrosion of metals is uniform. 
3. The protective effect of the inhibitor IFKhAN-114 in relation to the overall corrosion of carbon steel approaches $100 \%$ and reaches $85 \%$ for L62 brass and M2 copper in the presence of $0.2 \mathrm{vol} . \% \mathrm{CO}_{2}$. In the presence of $\mathrm{CO}_{2}(0.2 \mathrm{vol} . \%), \mathrm{NH}_{3}\left(20 \mathrm{mg} / \mathrm{m}^{3}\right)$ and $\mathrm{H}_{2} \mathrm{~S}$ $\left(10 \mathrm{mg} / \mathrm{m}^{3}\right)$ simultaneously, $Z$ reaches $74 \%$ (St3 steel), 99\% (L62 brass), and 60\% (M2 copper).

Table. The protective effect of IFKhAN 114 in air containing corrosion stimulants $(H=100 \%)$.

\begin{tabular}{|c|c|c|c|c|}
\hline \multirow{2}{*}{ No. } & \multirow{2}{*}{ Stimulants of corrosion in the air atmosphere } & \multicolumn{3}{|c|}{$Z, \%$ against corrosion of: } \\
\hline & & St3 Steel & L62 Brass & M2 Copper \\
\hline 1 & 0.2 vol. $\% \mathrm{CO}_{2}$ & 100 & 85 & 85 \\
\hline 2 & $20 \mathrm{mg} / \mathrm{m}^{3} \mathrm{NH}_{3}$ & 95 & 65 & 60 \\
\hline 3 & $10 \mathrm{mg} / \mathrm{m}^{3} \mathrm{H}_{2} \mathrm{~S}$ & 75 & 75 & 40 \\
\hline 4 & 0.2 vol. $\% \mathrm{CO}_{2}$ and $20 \mathrm{mg} / \mathrm{m}^{3} \mathrm{NH}_{3}$ & 87 & 74 & 95 \\
\hline 5 & 0.6 vol. $\% \mathrm{CO}_{2}$ and $60 \mathrm{mg} / \mathrm{m}^{3} \mathrm{NH}_{3}$ & 85 & 79 & 75 \\
\hline 6 & 0.2 vol. $\% \mathrm{CO}_{2}$ and $10 \mathrm{mg} / \mathrm{m}^{3} \mathrm{H}_{2} \mathrm{~S}$ & 95 & 85 & 65 \\
\hline 7 & 0.6 vol. $\% \mathrm{CO}_{2}$ and $30 \mathrm{mg} / \mathrm{m}^{3} \mathrm{H}_{2} \mathrm{~S}$ & 94 & 75 & 39 \\
\hline 8 & $10 \mathrm{mg} / \mathrm{m}^{3} \mathrm{H}_{2} \mathrm{~S}$ and $20 \mathrm{mg} / \mathrm{m}^{3} \mathrm{NH}_{3}$ & 75 & 90 & 70 \\
\hline 9 & $30 \mathrm{mg} / \mathrm{m}^{3} \mathrm{H}_{2} \mathrm{~S}$ and $60 \mathrm{mg} / \mathrm{m}^{3} \mathrm{NH}_{3}$ & 83 & 75 & 30 \\
\hline 10 & 0.2 vol. $\% \mathrm{CO}_{2}, 20 \mathrm{mg} / \mathrm{m}^{3} \mathrm{NH}_{3}, 10 \mathrm{mg} / \mathrm{m}^{3} \mathrm{H}_{2} \mathrm{~S}$ & 74 & 99 & 60 \\
\hline
\end{tabular}

\section{Acknowledgment}

This work was supported by the Russian Science Foundation, Grant No. 18-16-00006. The experimental results were obtained using the equipment of the Center for Collective Use of Scientific Equipment of TSU named after G.R. Derzhavin.

\section{References}

1. V.I. Vigdorovich, L.G. Knyazeva, A.N. Zazulya, E.G. Kuznetsova, N.N. Andreev, A.A. Uryadnikov and A.V. Dorokhov, Rossiiskaya sel'skokhozyaistvennaya nauka (Russian Agricultural Science), 2016, no. 1, 65-68 (in Russian).

2. V.I. Vigdorovich, L.E. Tsygankova, N.V. Shel, L.G. Knyazeva, A.V. Dorokhov and A.A. Uryadnikov, Int. J. Corros. Scale Inhib., 2018, 7, no. 2, 175-184. doi: 10.17675/2305-6894-2018-7-2-5

3. V.I. Vigdorovich, L.E. Tsygankova, A.N. Dorohova, A.V. Dorohov, L.G. Knyazeva and A.A. Uryadnikov, Int. J. Corros. Scale Inhib., 2018, 7, no. 3, 331-339. doi: $\underline{10.17675 / 2305-6894-2018-7-3-4}$ 
4. V.I. Vigdorovich, L.G. Knyazeva, A.N. Zazulya, V.D. Prokhorenkov, E.G. Kuznetsova, A.V. Dorokhov, A.A. Uryadnikov and O.A. Goncharova, Russ. Agric. Sci., 2017, 43, no. 4, 342-346.

5. N.V. Danyakin and A.A. Curuga, Electronic scientific journal of the Kursk State University, 2017, 13, no. 1, 1-7 (in Russian).

6. F.A. Ansari, C. Verma, Y.S. Siddiqui, E.E. Ebenso and M.A. Quraishi, Int. J. Corros. Scale Inhib., 2018, 7, no. 2, 126-150. doi: 10.17675/2305-6894-2018-7-2-2

7. A.P. Onegov, I.F. Yarabustovsky and V.I. Chernykh, Gigiena sel'skokhozyaistvennykh zhivotnykh (Hygiene of Agricultural Animals), Moscow, Kolos, 1977, 400 pp. (in Russian).

8. V.N. Kuz'min, V.F. Fedorenko and S.N. Sazonov, Spravochnik fermera (Farmer's Handbook), Moscow, Rosinformagrotekh, 2013, 616 pp. (in Russian). 